\title{
The closed world of biosphere 2
}

\section{Commentary}

In 1976 a series of scholars, including Ramón Margalef, James Lovelock, Lynn Margulis, and John and Nancy Todd signed a key consensus paper entitled "Ecological Considerations for Space Colonies," which was published in the Bulletin of the Ecological Society of America. In it they argued that "the question of space colonization should be explored," though they thought one should build a closed ecosystem on Earth before trying to build one in space. After all, "if stable and productive closed ecosystems could not be made to function on Earth they certainly would not function in orbit," and definitely not on the moon or on Mars. Their paper became the cornerstone of what is likely the most expensive ecological experiment ever, namely the Biosphere 2 project in Oracle, Arizona

Biosphere 2 was designed to provide a model for how humans should live within Biosphere 1 (the Earth). It was to be a fully enclosed ecosystem. The idea grew from discussions at the Synergia Ranch, a commune near Santa Fe in New Mexico, which included the architect Phil Hawes and the oil-magnate Edward P. Bass as members. They were inspired by the University of Arizona's Environmental Research Lab, which, since 1967, had been engineering a building that would integrate energy, water, and food into one ecosystem. Hawes, the building's principal architect, based his drawings on his 1982 outline of "Architecture for Galactic Colonies." It represented a continuation of his previous projects in New Mexico in the 1970s which focused on applying space ecosystem principles with circulation of energy and materials within a building. Bass, the investor, believed space technology would play a key role in the future in solving the world's ecological and social problems. His aim was to develop ecological technology to benefit energy efficiency, recycling, waste processing, sewage management, microbial composting, and other emerging solutions to the environmental problems on Earth. The development and patenting of such technologies were to provide Bass with a solid profit.

The scientific rationale for Biosphere 2 was to prove that the ecological colonization of space was a viable idea. The ecologists Dorion Sagan and Lynn Margulis described the scientific aims in Biospheres from Earth to Space (1989). They encouraged the reader, saying, "Imagine for a moment you are building a large ship that will travel through space," before plunging into a detailed analysis of how the science of ecology could enable people to "live in space indefinitely without the cost of importing supplies." Scientifically it was a question of figuring out the "carrying capacity" of a closed ecosystem with respect to how large a crew of astronauts an artificial biosphere could support. "Successfully running a new biosphere would show people what it takes to make it in our beloved old one," they argued, pointing to the relevance of such ecological research to "astronauts" making a living onboard "Spaceship Earth." Moreover, "to settle Mars" with new populated biospheres could provide "protection in case of nuclear war" and "curb global population growth" on Earth. Thomas Paineparticularly argued that "closed ecology systems can free us from Malthusian limitations by making the Solar System our extended home."
Volume I Issue 2 - 2017

\author{
Peder Anker \\ Department of Environmental Studies, New York University, \\ USA \\ Correspondence: Peder Anker, Department of Environmental \\ Studies, Gallatin School of Individualized Study, New York \\ University, New York, NY I00 12, USA, Tel +917 690 548I, \\ Email peder.anker@nyu.edu
}

Received: August 21, 2017 | Published: November 10, 2017

The aim of the Biosphere 2 was also to build a shelter in which Bass and his friends could survive in co-evolution with thousands of other species in case the eco-crisis turned Biosphere 1 into a dead planet like Mars. Scientists and designers of Biosphere 2 fashioned themselves in the image of the Biblical Noah. They believed that "Glass Ark" could secure their personal survival while at the same time rescue some of the world's biodiversity.

Biosphere 2 was completed in 1991 and sealed, after eight "biospherians" dressed in space suits had marched through the airlock. They promised to stay there for two years. "The project's participants say it can show how to colonize other planets or survive ecological catastrophe on this one," a journalist reported from the widely publicized event. Soon rumors circulated about a smuggled bag of supplies to hungry biospherians, and fresh air being pumped into the building. With crew members suffering from lack of oxygen, a decision was made to pump more of it into the building, though it effectively ruined the value of the experiment since the building was supposed to be sealed. Nature did not easily conform to the space cabin concept, later reviews of the project claimed. It was apparently a relief to the crew when they-in space suits-marched out of the airlock in September 1993. Despite the trouble, the Biosphere 2 building became a model for ecological architecture and set the standard for a growing field.

The questionable result of the Biosphere 2 experiment led to a dramatic layoff of most of the staff in the spring of 1994. Bass thought "it was time for the project to start making a profit," and would consequently gear the managerial focus towards ecotourism. Over half a million visitors had so far paid $\$ 12.95$ each to learn about ecological colonization of Mars, and with the "biospherians" out of Biosphere 2, ecotourists could now rent rooms within the building and visit a restaurant to experience what ecological life on Mars soon would be like. This was much in line with the thinking of ecologists, who believed constructing ecological microcosms was a helpful way to educate people about ecology since it could provide pupils with a quick-to-learn overview of the complexity of nature's economy.

\section{Acknowledgements}

None.

\section{Conflict of interest}

Author declares that there is no conflict of interest. 